\title{
Esophagus Partial Response GvHD
}

National Cancer Institute

\section{Source}

National Cancer Institute. Esophagus Partial Response GVHD. NCI Thesaurus. Code C126717.

An NIH esophagus score that has decreased by 1 or more points. 